\title{
Decision making in gates: Based on formal basis or gut feeling?
}

\author{
Functional Product Development, \\ Luleå University of Technology, \\ 97187 Luleå, Sweden \\ E-mail: asa.kastensson@1tu.se \\ E-mail: christian.johansson@1tu.se \\ ${ }^{*}$ Corresponding author
}

Åsa Kastensson* and Christian Johansson

\begin{abstract}
Manufacturing companies continuously deal with development of innovations. Many of these are cancelled on the way, in gate meetings. This paper investigates why technologies are cancelled, and on which basis managers make decisions. The paper is based on a study from the automotive industry with interviews with different stakeholders in the gates. The most common reasons for stopping projects were time, cost and technology readiness. Gut feeling is found to be an important factor when evaluating projects. This paper concludes that managers need to understand the role of intuition and query for this subjective information in addition to objective measures.
\end{abstract}

Keywords: decision making; stage-gate; product development; product innovation; technology development; automotive industry.

Reference to this paper should be made as follows: Kastensson, $\AA$. and Johansson, C. (2011) 'Decision making in gates: Based on formal basis or gut feeling?', Int. J. Technology Intelligence and Planning, Vol.

Biographical notes: Åsa Kastensson is an industrial PhD Student affiliated to Functional Product Development, Luleå University of Technology, Sweden, and her fields of interests are innovation processes and the management of innovation projects. She has a technical educational and industrial background. She has been a project manager for product development projects in academia as well as in industry.

Christian Johansson is a Researcher in Functional Product Development at Luleå University of Technology. His main research interests include knowledge management, product development and support for decision making. The focus of the current research is related to use of knowledge management in stage-gate governed product development to support decision making.

\section{Introduction}

The ability to provide customers with innovations will make companies successful and offer competitive advantage. Thus, it is commonly discussed that innovation is important for companies to succeed in a global and competitive market (Davila et al., 2007; 
Tidd et al., 2001). Increasing environmental concerns are even stronger incentive to innovate. Environmental regulations are placing immense pressure on manufacturing industries and this pressure will undoubtedly increase in the future. This will challenge the companies' innovation capabilities. It will require entirely new solutions and thinking to develop products that meet the demands that will apply in the future. For certain industries, this may mean a paradigm shift in terms of new technologies, products and processes (Christensen, 2006).

Manufacturing Business to Consumer (B2C) companies, for example in the automotive industry, are required to deal with not only increased technical complexity but also complexity related to the development process, such as, by assuring decreased lead times and an increased social complexity in the design team, among other things, by involving more disciplines. Generally, this kind of innovation context has to make use of cross-functional teams (Wheelwright and Clark, 1992), perform more tasks in parallel (Andreasen and Hein, 1987) and make decisions based on preliminary information (Flanagan, 2007). Furthermore, there is a challenging interface with the customer. Customers often find it difficult to express their expectations on future products, even if they know what they like with today's versions (Clark and Fujimoto, 1991). The difficulties in predicting future needs make it challenging to choose which innovation project to pursue.

Innovating is associated with creativity and idea-generation but the ideas have to be put to work. The ability to implement the ideas as innovations is a major concern (Levitt, 2002). There are numerous examples of ideas that do not reach an implementation stage.

Innovation projects are evaluated and assessed in decision gates (Cooper, 2001) for further implementation in the products. In the gates, decisions are made about the future of the innovation projects. Currently, innovations are cancelled in or in front of the gates. Therefore, decisions made in the gates are of major importance for future implementation of new ideas.

The purpose with this study is to understand why technologies are cancelled in gates and on which basis involved managers make their decisions.

This paper aims to not only contribute to theory with empirical data from the automotive industry, but also explore on which ground decisions are made.

First, the methodological approach for this case study is outlined, with notes on the industrial context, as well as on the research method applied. Thereafter, the relevant theoretical areas are reviewed to provide a basis for the paper, followed by the main empirical findings of the study, focusing on relevant aspect of the gate. Finally, the results are discussed, and notes on conclusions and managerial implications are provided.

\section{Methodological approach}

The study in this paper is part of a research project that aims to contribute to an increased understanding of how the company manages innovation activities, and how they can improve their management. The company has a background as a leading firm of technological innovations and is a manufacturer in the automotive industry.

Recently, the company has gone through a period of re-organisation and new ownership. The company is adapting to the principles of lean production (Womack et al., 2007 ) to create efficient development and manufacturing processes. In line with this, a main concern is how to implement new ideas and innovations in the products. Currently, 
many ideas do not reach the implementation stage. New technologies are stopped in or in front of the gates. The development process within the company is a stage-gate process (Cooper, 2001), which consists of several stages where each stage composes several activities needed for the progress of the project. To be able to move on to next stage, the project must pass a gate, where specific deliverables for that gate are needed. Here, the output from the gate will be a 'green' or a 'red' decision, where green means that the gate will be opened and red that it will remain closed.

To achieve the stated purpose, a qualitative research approach was adopted, as the focus is on gaining a deeper understanding of a real-life context (Yin, 2009). The research methodology is inspired by an action research perspective meaning, among other things, that the research is grounded in lived experience, and that the researcher works with - rather than simply study - people (Bradbury, 2003). The goal of the research is that the outcome of the research could be implemented in the environment that is under study but also to generate new knowledge within the field (Checkland and Holwell, 1998).

The data was derived from semi-structured interviews with an open-ended character (Yin, 2009) with managers from two different projects within the company. Interviews as a method of data collection provide a greater breadth owing to its qualitative nature (Fontana and Frey, 1994). The choice of two different projects as two cases increases the external validity, and thus the possibility to generalise the results, by comparing the two cases (Yin, 2009). Both projects are product projects that are characterised by complexity both in terms of components, systems and functions, and thus the decision making, but also because these projects involve many people from different functional areas and departments, and have a relatively long time frame. Case 1 is an ongoing project and case 2 is a finalised project with a launched product on the market. These are hereafter denoted as project 1 and project 2, respectively. A significant difference between them is that the company has undergone major changes during the time the projects have been running, from a company with globalised product development to a small independent manufacturer.

In total, six informants were interviewed, where each interview lasted on average for one hour. The informants represented three complementary areas with different responsibilities in the gate process: Project Management, Chairmen of the Steering Group and Portfolio Planning Management. They were selected on the basis of having long experience within the company - more than 10 years - as well as within their respective role, thus being accustomed to their roles from many previous development projects.

The project leader is responsible for new programmes and thus the information available before a gate as a basis for decision making. He prepares all necessary material for the specific gate and is responsible for the content. This preparation is done together with the project group. The project leader has mandate to do internal balances within the project as long as the project reaches its overall goals.

The chairman of the decision board is responsible for the programme and reports directly to the CEO. He decides if the gate should open.

The manager of portfolio planning is responsible for new technologies, to make sure there is a balanced technology list.

The rationale for choosing these informants is to perceive different aspects of decision making in a gate because these informants represent three diverse roles "around the table" at a gate. This means that results of the study are highlighted from 
complementary viewpoints, thus promising to provide an increased and deeper understanding of the gates.

The data from the interviews were recorded and partly or fully transcribed into plain text. The interview questions were grouped into different topics, to search for themes (Miles and Huberman, 1994) that could be compared with theory, which will increase the external validity (Yin, 2009). To aid this analysis, a table was created with relevant comments from informants, divided not only between the roles but also between the projects. A cross-sectional analysis of the material was performed and the data was reduced (Miles and Huberman, 1994) by forming a number of themes from the analysis of the material.

Additionally, in the analysis, results from previous investigations of similar nature, by one of the authors, in other industrial sectors were drawn upon to validate the results further, as well as make sense of the information found.

\section{Theory}

\subsection{Stage-gate}

The stage-gate process (see Figure 1), developed by Cooper (2001), is a process that could be defined as a roadmap for the phases and control gates that project leaders and teams use to move through when proceeding the project from idea to launch. Each stage consists of specific activities with the purpose to develop the product from one gate to the next. Cooper (2008) expresses these activities as information and knowledge creation that brings input to the gate. The progress of the project is evaluated and compared with the predefined criteria at a gate. To open the gate, all the criteria has to be fulfilled (Cooper, 2008). Cooper (2001) defines four options for the project at a gate: 'go', 'recycle', 'hold' and 'kill'.

Figure 1 Stage-gate process

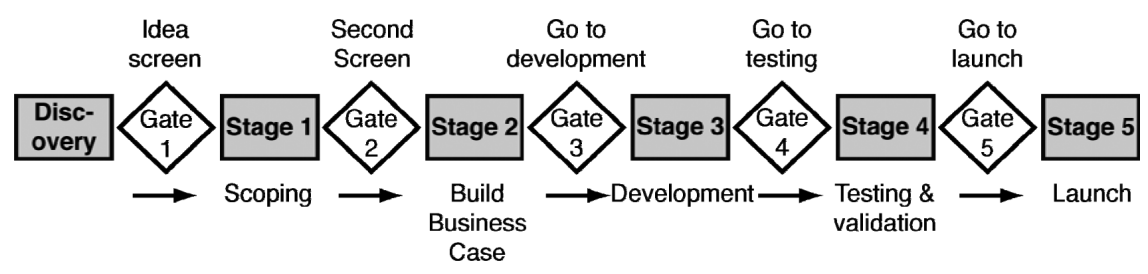

Source: Adapted from Cooper (2001)

By dividing decision making into sequential events (i.e., gates), the risk with new products is expected to be reduced since the project will be evaluated during each gate and could be stopped, or killed, if it is not successful (Christiansen and Varnes, 2006). According to Cooper (2001), the decisions at a gate must have a standardised format to undertake rational decision making. Decision making at gate meetings is supposed to follow the rational model for decision making (March, 1999). 


\subsection{Evaluation criteria}

In product development, there are typically three sets of evaluation criteria: market criteria, product criteria and financial criteria (Ronkainen, 1985), i.e., considering if there is a market for the product, if the concept can be transformed into a product and if the product can be produced in a profitable way, respectively. In addition to these, Tzokas et al. (2004) also identified process and intuition as criteria dimensions.

During the course of a product development project, the criteria will change and, in particular, the relative importance of them will change (Ronkainen, 1985; Hart et al., 2003; Tzokas et al., 2004).

Hart et al. (2003) also found similar indications, where more implicit and product-level criteria were more important in the earlier gates, and more business-level criteria gained importance in the latter gates:

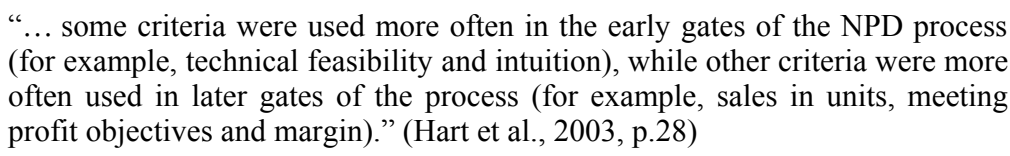

Intuition is particularly important in the early phases, owing to the amount of uncertainties that typically is in early phases of projects (Hart et al., 2003).

Hart et al. (2003) also found that professional training of decision-makers in terms of functional areas influence which kind of evaluation criteria is being used, indicating that this could also be culturally influenced to some extent.

\subsection{Decision making}

The quote "Design is the evolution of information punctuated by decision-making" (Ullman, 2001, p.3), by Ullman (2001) highlights the central role that decision making plays in product development. Mintzberg et al. (1976) defined decision making as a commitment to action and they develop a decision process consisting of three phases: identification, development and selection. The identification phase consists of recognition and identification, the development phase of search and design routines and the selection phase consists of screen, evaluation of choices and authorisation routines. Deck (2002) defines decision making as:

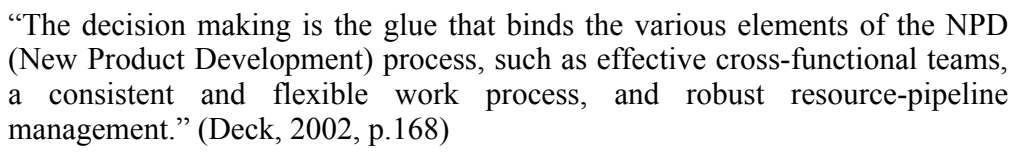

"The decision making is the glue that binds the various elements of the NPD (New Product Development) process, such as effective cross-functional teams, a consistent and flexible work process, and robust resource-pipeline management.” (Deck, 2002, p.168)

Rational decision making (March, 1999) prescribes that knowledge of all alternatives and consequences are available and Scott (2000) discusses rational choice theory as if all social action always is rationally motivated and calculative. In practical situations, rational decision making is rare (Simon, 1979) and related to what March (1987) calls the ambiguities of choice. Therefore, a satisficing rationality, i.e., being rational in a bounded way, is proposed (Simon, 1979; Eisenhardt and Zbaracki, 1992). Simon (1979) also argues that rational decision making provides optimal solutions in a simplified world. In reality, all alternatives are seldom known and all consequences are not possible to be thought of. This is characteristic to projects in early phases and innovation projects where the degree of elaboration naturally is low and the knowledge about the projects 
conditions will change over time (Engwall, 2003). By extension of this argumentation, Hayashi (2001) means that when not all information is available it is important for decision-makers to trust emotions and intuitions, where experience is an important basis for such decisions (Eisenhardt, 1990). How do managers handle decision making in gates of projects in early phases or innovation projects where the consequences for the company is unknown? Do they trust their intuition when making decisions about the projects future in a gate or is every decision based on verified knowledge? Christiansen and Varnes (2006) found in a study that decision-makers within a company did not apply rational decisions in a gate according to March's (1999) rational decision theory.

\section{Empirical findings: decision making in gates}

This section presents the answers from the interviews with the informants about decision making in gates, containing both why projects are cancelled and on what basis involved managers make their decisions. Four areas were crystallised to be of interest in these discussions:

- challenges with decision making at a gate

- reasons why a technology get stuck in a gate

- the role of gut feeling

- formal basis for decisions and reliability of the information supporting the decision.

All of them are presented here.

\subsection{Challenges with decision making at a gate}

What are the greatest challenges when evaluating a project at a certain gate and deciding how to proceed with this particular gate?

The project leader from project 1 says that a challenge in early gates is to balance the content in the project relative cost.

Another challenge is to judge if the technologies have reached a specific readiness level so that it is possible to realise them and minimise the risk when introducing the technologies in the project. The chairman of the decision board has the same opinion. He means that the biggest challenge in an early gate is to identify the risks associated with the project and technology content. He continues:

\footnotetext{
"In later gates you can decide on concrete problems which are much easier since a concrete problem can be subjectively evaluated and experienced as a customer."
}

When a project reach latter gates, the consequences are known and the presence of hardware enables a physical evaluation. He means that new technologies entail greater risks and the capacity to quantify the risks will control the decision if the project should move on or stop to be able to manage these risks.

Contingency planning and catch-up actions is a topic that is challenging in the gates. The project leader from project 2 means that the biggest challenge is to accept a deviation from a target that is not fulfilled. This is difficult, not only because you really want to achieve defined targets, but also because it is difficult to get the organisation to accept 
deviations and manage these. The chairman in the same project highlights that the biggest challenge is to decide if the project should stop to take care of the problem, which could delay the programme, or if the project should move on and facing up to the risk that brings. Risks are greater when there are new technologies that the company lacks experience with, and it is, therefore, more difficult to estimate the consequences that a deviation will bring. Risks in standard product development are easier to judge.

\subsection{Reasons why a technology get stuck in the gate}

What are the main reasons for new technologies to not pass a gate? This question includes new technologies belonging to a product programme.

Time and cost is extremely important in this context. According to the chairman from project 1 , the reason why technologies are cancelled from a product programme depends mostly on time and cost and if it is removed from the portfolio the reason is most often that the company cannot afford it.

Similarly, the project leader from project 1 says that the most common argument is money. He continues to say that it is difficult to know whether a new technology that will replace the existing one will be profitable, which influences the decision:

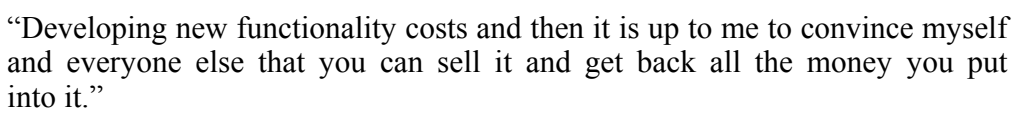

"Developing new functionality costs and then it is up to me to convince myself and everyone else that you can sell it and get back all the money you put into it."

He says that it is a question of what risks the company is willing to take with new concepts. Changing functions that are expected by the users to be in a certain way could in the end result in that it will not be possible to sell the product since it is perceived as too odd. The chairman from project 1 expresses that the company strategies and the brand strategies decide what technologies should stay on the list.

The manager of portfolio planning expresses that a technology project does not pass a gate if the technical solution is not beneficial in terms of technical feasibility. He also means, as the other informants, that most often technologies are cancelled because of time and cost.

Furthermore, the project leader from project 1 also says that another reason that a technology would not pass through the gate is that it has not reached required readiness level from a technical perspective resulting in a major risk for the receptive car programme. Both the project leader and the chairman from project 2 mean that the main reason for a project to get stuck in a gate is that development has not finished and the reason for that are initially too little resources in the beginning of the project, a too tight time plan and disciplinary problems.

\subsection{The role of gut feeling and formal basis for decisions}

When you hold a project, is it based on a formal basis or gut feeling? This question comprehends what level and type of material is acceptable to make decisions at a gate, whether the decisions are made only on proven facts or if intuition is involved in decision making.

The chairman expresses that overall there are estimations that need to be made at a gate. He continues that he has to estimate what will happen 'if' he decides to follow this step, he has to do a 'what-if' analysis but continues: 
"To do a risk assessment is based as much on a feeling as actual data ... a hope or whatever you will say."

He also says that it is dependent on how concrete the risk is. An evaluation of a less concrete risk will be more based on gut feeling.

The two project leaders express that all communication has to be concrete. One of them means that this is something he has learned many times:

"This is a part of the job, to go to a gate and be concrete. You got the feeling but that is something you have to try to concretise."

Then, he continues that the feeling is when he is valuing a person and if he can trust in what that person says. The project leader from project 2 says that it is when he is judging how many 'red' deliverables (i.e., substandard deliverables) are too many, i.e., the amount that can be managed and still continue running the project, that gut feeling plays a major role:

"... judge how many red deliverables that will be the straw that broke the camel's back ... this many we can manage and still continue the project."

The chairman from the same project says that there is always a rational decision material; however, the assessment of this material is individual dependent. You judge it based on who has delivered it.

\subsection{Reliability of the information supporting the decision}

What is the reliability of the information presented at a gate? This question includes how the informants trust in the information material presented at a gate. It contains not only the decision material during the gate, but also the information presented to the managers as preparatory material ahead of the gate.

The project leader from project 1 says that the materials are almost always too optimistic. The employees in the company want to do so much in a short time but he means that it is important to follow a process and take time to finalise; otherwise, it could give resulting effects in the end that could be hard to grasp. He also says that it is difficult to do things elaborately in an early stage of a project and that it is difficult to predict what will happen when the project is applied in a certain car programme and he continues:

"There are always surprises in every situation. When you are developing new technology unexpected consequences appear, things you did not think about."

The project leader from project 2 means that he trusts what is written in the basic data; however, he knows that he in the data from certain departments will only end up with fulfilment of three out of five properties.

"They lack a complete picture of the impact analyses in the material and it is often from the same people and departments, and moreover, they do not deliver on time. The worst material you receive last. This is individual dependent and after a while you know who to trust."

The chairman from project 1 expresses that the quality of the material is shifting a lot and that he has learned whom he can trust, which affects the decision that has to be made. He continues that he makes a back-tracing afterwards when he has the result, basically a lesson learned. The chairman from project 2 means that you need to know the individuals responsible for the material and continues: 
"It is not the decision basis you put your faith in, it is the individuals."

He says that he has to feel and know where to interfere and where not to. It is often the same areas in the organisation that have problems. Similarly, the manager of portfolio planning also means that the quality of material is shifting, where trust differs between different departments, which he has learnt by experience. He continues that it is really important that the project leader knows the organisation, and he even means that this is something he is obliged to.

"Then there are of course various trusts in different departments. There are those who never take a risk and those who happily jumps at risks and report the project as completed."

The informant says that there are people who decide to choose uncertain or ambiguous concepts that are unclear in terms of the consequences they imply for the project in form of time, cost and technical issues. This could delay a whole programme and in the end delay the launch of the product with major consequences. He summarises that the technical assessment often is too optimistic. Engineers are trained to see opportunities instead of problems and this approach is something earned from the engineering education.

\section{Discussion}

From this study, we find that, unsurprisingly, cost and time holds an important place in the gate meetings. However, it is interesting to see the important role technology plays here as well. Readiness of technology is a significant part in the decision being made; if the technology has not reached a sufficient readiness level, it will pose a risk to the company to take forward into a car programme. There is an interesting parallel to be made with the most widely adopted framework for assessing technology readiness, or technology maturity, the Technology Readiness Level (TRL) (Mankins, 2002) tool developed by NASA and used by many more companies in several sectors. One of the main advocates for using the TRL framework, the US General Accounting Office (GAO), reports on cost and schedule overruns when technologies are transferred into programmes too early (i.e., at too low maturity) showing the severity of this issue (Schinasi, 1999). There is a need to be able to quantify the risk in the gate, where new technologies naturally entail greater risk.

However, not always is it possible to judge solely on this issue. Another risk is how the technology later on is perceived by the customer. Sometimes, a technology may be 'ready', however it might still not be worth making the change, or investment, because it is a change for the user, that either may not pay off or it is, as one informant said, too odd. Therefore, it will not return the value. Conversely, there are times when things still need to be pushed through, or where it is worth making the change, and here the brand strategy is a guiding star for the company.

The empirical results show that decision making in a gate is not only based on facts and actual figures, but also often based on gut feeling and intuition. Things have to be concrete, but there is still a place for gut feeling when making judgements. This is especially true for the early stages, where informants state that it is difficult to be very elaborate. Tzokas et al. (2004) found that firms' evaluation criteria differ depending on which phase the project is in, where, for instance, the role of intuition is more 
predominant in the early phases where uncertainties are higher (Hart et al., 2003), only to reduce throughout the project. However, it will never disappear completely.

This is also consistent with earlier findings in another industrial sector (ref to self). The informants perceived that the current trend pointed towards more fact-based decision-making in gates. Yet, they also expressed that such practice ignores value, intuition and gut feeling completely. Part of the decision-maker's task in the gate is to query the project leader and the project team for this factor, because a situation where the numbers add up but where the team do not believe them or do not feel comfortable with them is potentially hazardous for the continuation of the project. It is important to find a timely mix between facts and intuition, because not having any facts and only intuition will not work either. With 'timely mix', we here mean that the decision-makers have to acknowledge the difficulty of having all the facts in the early phases and rely more on intuitions, with clear plans for gradually arriving at more facts and data as the project moves on.

According to Cooper (2001), objectivity is predominant at a gate. He also means that the project manager should not take part in the gate since there is a risk he could influence the decision-makers and thereby adventure the rationality in decision making (Cooper, 2001). This is in contradiction with what the informants in this study express. Valuing the material based on whom or which department is responsible is an important factor according to informants. In early gates when the project and the technology content are unclear and not concretised, it is not possible to have all data and alternatives and foresee all consequences. In these gates, rational decision making is difficult to achieve since it is characterised by that knowledge of all alternatives and consequences are available.

Coming back to the empirical data, we also found that the informants think that the basis for decision is often too optimistic, which can pose a risk to the project. An important factor in valuing these decisions is to know the people who are behind the material presented at the gate. Here, the informants quote experience as an extremely important ingredient for a decision-maker to have. Experience of which department, which supplier, or even which person is conservative, realistic or optimistic in presenting their information to the gate meeting is invaluable, because these are usually repeatedly the same ones.

\section{Conclusions and managerial implications}

In this paper, an empirical investigation, where managers from two projects representing three diverse roles in gate decisions, has been presented with the purpose to understand why innovations are cancelled in gates and on which basis involved managers make their decisions. The most common reason for projects to stop in a gate is, not surprisingly, time, money and TRL. A conclusion of this is that there is a need to be able to measure TRL of a new technology before implementing it in the product. The empirical result also shows that decision making in a gate are not only based on verified (objective) figures and data but also most often rely in the trust the decision-makers have in responsible persons and that this type of knowledge is achieved through long experience within the company. Also, a rational decision making in early gates is not applicable in practice. 
Therefore, a large portion of intuition is important in decision making in these early phases but even in latter gates not all facts are available and this means that there still is a part of intuition included in the decision making. On the basis of this, three managerial issues for decision making in gates could be highlighted:

- Making it possible to measure TRL increases the confidence level for decision-makers when a new technology will be introduced in a product project. A technology readiness tool will be helpful.

- Making decisions on preliminary and insufficient data will always be something decision-makers have to deal with, in early phases with a larger portion of intuition, which will decrease during the projects life but will never disappear totally. Managers have to trust their intuitions and dare to make decisions without all the facts on the table.

- It is essential for managers to be able to gather right people with the right experience and expertise in mainly early gates to ensure that the confidence in decisions is sufficient.

In the course of this study, we see that it is interesting to evaluate gate criteria as next step. New technologies are evaluated and judged in gates but how do these criteria look like to support innovation projects?

\section{Acknowledgements}

We express our gratitude to the company representatives and the informants, who participated in the interviews. Also, the company is acknowledged for providing research funding.

\section{References}

Andreasen, M.M. and Hein, L. (1987) Integrated Product Development, IFS (Publications) Ltd/Springer-Verlag, Berlin.

Bradbury, H. (2003) 'Action research: an opportunity for revitalizing research purpose and practices', Qualitative Social Work, Vol. 2, No. 2, pp.155-175.

Checkland, P. and Holwell, S. (1998) 'Action research: its nature and validity', Systemic Practice and Action Research, Vol. 11, pp.9-21.

Christensen, C.M. (2006) The Innovator's Dilemma:When New Technologies Cause Great Firms to Fail, Collins Business Essentials, New York.

Christiansen, J. and Varnes, C. (2006) 'The ignorance of information at gate meetings', Paper presented at the 13th International Journal of Product Development Management Conference, Milan, Italy, EIASM.

Clark, K.B. and Fujimoto, T. (1991) Product Development Performance, Harvard Business School Press, Boston.

Cooper, R.G. (2001) Winning at New Products: Accelerating the Process from Idea to Launch, 3rd ed., Basic Books, New York. 
Cooper, R.G. (2008) 'The stage-gate idea-to-launch process - update, what's new and nexgen systems', The Journal of Product Innovation Management, Vol. 25, No. 3, p.213.

Davila, T., Epstein, M.J. and Shelton, R. (2007) The Creative Enterprise: Managing Innovative Organizations and People, Vol. 3, Praeger Perspectives, London.

Deck, M. (2002) 'Decision making; the overlooked competency in product development', in Belliveau, P., Griffin, A. and Somermeyer, S. (Eds.): The PDMA Toolbook for New Product Development, John Wiley \& Sons, New York.

Eisenhardt, K.M. (1990) 'Speed and strategic choice: How managers accelerate decision making', California Management Review, Vol. 32, No. 3, pp.39-54.

Eisenhardt, K.M. and Zbaracki, M.J. (1992) 'Strategic decision making', Strategic Management Journal, Vol. 13, pp.17-37.

Engwall, M. (Ed.) (2003) Produktutveckling Bortom Kunskapens Gränser: Mot en Osäkerhetens Grammatik, Studentlitteratur, Lund.

Flanagan, T. (2007) 'Externalizing tacit overview knowledge: A model-based approach to supporting design teams', Artificial Intelligence for Engineering Design, Analysis and Manufacturing: AI EDAM, Vol. 21, No. 03, pp.227-242.

Fontana, A. and Frey, J.H. (Eds.) (1994) Interviewing: the Art of Science, Sage, Thousand Oaks, CA, USA.

Hart, S., Hultink, E.J., Tzokas, N. and Commandeur, H.R. (2003) 'Industrial companies' evaluation criteria in new product development gates', The Journal of Product Innovation Management, Vol. 20, No. 1, pp.22-36.

Hayashi, A.M. (2001) 'When to trust your gut', Harvard Business Review, Vol. 79, No. 2, pp.59-65.

Levitt, T. (2002) 'Creativity is not enough', Harvard Business Review, Vol. 80, pp.137-145.

Mankins, J.C. (2002) 'Approaches to strategic Research and Technology (R\&T) analysis and road mapping', Acta Austronautica, Vol. 51, pp.3-21.

March, J.G. (1987) 'Ambiguity and accounting: the elusive link between information and decision making', Accounting, Organizations and Society, Vol. 12, pp.153-168.

March, J.G. (1999) The Pursuit of Organizational Intelligence: Understanding How Decisions Happen in Organisations, Blackwell Business, Malden, MA.

Miles, M.B. and Huberman, A.M. (1994) Qualitative Data Analysis: An Expanded Sourcebook, Sage Publications Inc., London.

Mintzberg, H., Raisinghani, D. and Théoret, A. (1976) 'The structure of 'unstructured' decision processes', Administrative Science Quarterly, Vol. 21, No. 2, pp.246-275.

Ronkainen, I.A. (1985) 'Criteria changes across product development stages', Industrial Marketing Management, Vol. 14, No. 3, pp.171-178.

Schinasi, K.V. (1999) Better Management of Technology Development Can Improve Weapon System Outcomes, United States General Accounting Office Report (GAO/NSIAD-99-162). Washington DC.

Scott, J. (2000) 'Rational choice theory', in Browning, G., Halcli, A. and Webster, F. (Eds.): Understanding Contemporary Society; Theories of the Present, Sage, Thousand Oaks, CA.

Simon, H.A. (1979) 'Rational decision making in business organizations', The American Economic Review, Vol. 69, No. 4, pp.493-513.

Tidd, J., Bessant, J. and Pavitt, K. (2001) Managing Innovation, 2nd ed., John Wiley and Sons Ltd., London.

Tzokas, N., Hultink, E.J. and Hart, S. (2004) 'Navigating the new product development process', Industrial Marketing Management, Vol. 33, No. 7, pp.619-626. 
Ullman, D.G. (2001) 'Robust decision-making for engineering design', Journal of Engineering Design, Vol. 12, No. 1, pp.3-13.

Wheelwright, S.C. and Clark, K.B. (1992) Revolutionizing Product Development: Quantum Leaps in Speed, Efficiency, and Quality, The Free Press, New York.

Womack, J.P., Jones, D.T. and Ross, D. (2007) The Machine that Changed the World, Simon \& Schuster, London.

Yin, R. (2009) Case study Research: Design and Methods, Sage Publications Inc., London. 